\section{Can British defense firms diversify? The case of Nanoquest and the limits to dual-use theories}

\section{Jonathan Michael Feldman}

$\mathrm{T}$

his article investigates the case of Nanoquest, a small diversification project tied to BAE Systems' earlier incarnation as British Aerospace (BAe). ${ }^{1}$ It is shown that a military firm can have success when diversifying into civilian markets, but that the process can be sabotaged by managerial interference. In the process, the article illustrates the limited utility of dual-use theories when they are used to explain certain diversification outcomes. Rather than being merely issues of technological similarities or limitations, diversification success and failure are shaped by managerial power relationships. Discourses about the relatedness of military and civilian technologies, networks, learning, and information exchange alone cannot fully explain how and whether diversification barriers are overcome.

The article proceeds to show how the Nanoquest case relates to the wider economic conversion and disarmament debate. The case shows that when market or product similarities exist between military and civilian firms, diversification - even when successful - is not easily accomplished. This finding goes against claims made by some dual-use scholars who argue that similarities between military and civilian products help explain why diversification barriers are often slight. ${ }^{2}$ These claims are compared with those of another body of scholarship and theorists who, beginning with institutional economists like Veblen, argued that the political power of managers and capitalists can create barriers to growth and innovation. To a certain extent such arguments were later echoed by certain management theorists. ${ }^{3}$

The article then explores the origins of the Nanoquest company. One key aspect of its development lies in the history of how the firm's resources were organized as part of a wider context defined by different components of a larger family of companies and managerial structures at British Aerospace. Some of these structures, like a special diversification unit in the firm, helped facilitate the company's move into civilian markets.

A third section shows how Nanoquest actually diversified, a process supported in part by organizational innovations like British Aerospace Enterprises, the name of a special unit designed to promote diversification in the firm. This section shows that the ability of defense firm capacities to become related to civilian technology and markets is based on an historical process of learning and reorganization. Relatedness cannot always be defined a priori, as dual-use theories sometimes imply, but often is created. After this process of creation, the diversified firm appears more related to its military origins than it actually was.

The article therefore shows two sides to arguments of relatedness, which are a central part of many dual-use theories. First, learning helps deepen relatedness. Second, higherlevel managers decide how much they want potential paths of relatedness to develop. Firms are not like trains on a track, but are more like free-moving, multi-directional kinds of transport

vehicles. Given the power that defines choices, learning is mediated by politics. The actual history of Nanoquest bears out many of the arguments made by institutiona economists and managerial theorists, in particular that resource development is mired in power struggles within the firm.

Nanoquest and the debate about economic conversion and diversification

Military specialization

In theory, defense firms' development of new civilian products and entry into new civilian markets can make several important contributions. First, it can provide alternative jobs for defense engineers and industrial workers after military contracts or budgets are cut back. Second, it can help diminish political opposition to military cutbacks by giving defense-dependent communities civilian employment alternatives. Third, it can release valuable resources in design and manufacture for the civilian economy. ${ }^{4}$

In the debate over whether defense firms' shift into new markets and products is possible, and what barriers might be encountered, one view is that defense firms are so specialized as to find it impossible to shift into civilian markets, or that they can do so in only a very narrow range of areas. Others point to specialized defense engineers more interested in military performance than low cost. A key barrier is the high overhead operations of military firms, based in part on specialized equipment and on accounting procedures designed to meet military regulations or other requirements. Thus, Britain's Labour Party in a 1995 manifesto proclaimed that "past attempts at conversion - in its crudest form, switching a factory's production line from tanks to tractors - have usually failed, and have little relevance to the modern workplace." The goal should be to diversify a company's "capabilities and expertise, rather than its product base." This notion sees failure tied to some technical deus ex machina.

Yet, military specialization has been overcome in many defense firms by creating lean production platforms, by learning via trial and error methods, or by collaboration with civilian counterparts with expertise in key product or market segments. Defense firms can learn how to overcome barriers and reorganize themselves. ${ }^{6}$ In some cases, 
organizations can play the role of "dual actors," bridging military and civilian applications. ${ }^{7}$ Some have even suggested that conversion is relatively easy, because of similarities between military and civilian technologies or markets. ${ }^{8}$

The Nanoquest case provides a British example of the conditions under which diversification can be successful, albeit into a security-related, but not military, market. Yet, the case also reveals that even when civilian products and markets are closely related to military ones, failure (or constraints on the diversification process) is still possible. The reason is that key barriers to defense firms entering civilian markets are not necessarily based on economic or technical considerations, but also on political ones, that is, the politics of how firms are organized. In the Nanoquest case, success came to depend on the ways British Aerospace created structures to help mitigate (to a certain degree) power structures that blocked diversification. Described here is the extent to which questions of technology and hypothesized barriers to diversification were overcome, but political barriers to innovation were not.

\section{The differences between dual-use frameworks and institutionalist arguments}

The idea of dual use has been used to refer to technologies that have "or can have both military and civilian applications." But "even when military and commercial interests are technically compatible, non-technical factors such as standards and security restrictions can get in the way of dual-use." ${ }^{10}$ Conflicts between military and civilian objectives extend far beyond export controls and classification requirements to problems associated with managerialism, that is, the extension of defense agency managerial power and military objectives. Civilian divisions within prime defense contractors like BAE Systems (or British Aerospace) have been weaker than their military counterparts because the combination of sizeable, profitable military contracts and defense specialization has oriented top managers in multi-divisional defense firms to favor military markets. ${ }^{11}$ Simply put, military managers often win in the competition for money, staffing levels, and quality engineers. This competition echoes a macro competition in which the military economy diverts resources from civilian needs and constrains overall growth. ${ }^{12}$

Conceivably, even the most arcane technologies may have civilian applications because of the skills, experiments, and know-how of innovators working on various projects in the course of developing military technologies. These skills accumulate during multiple projects and careers and cannot be measured simply by examining a single case of technology transfer or a given technological application. The fungible character of innovative resources therefore becomes a central question. Some have argued that military engineers are often indifferent to designs that minimize cost as they are often geared to military performance. Independent of the knowledge that defense engineers gain during their careers, many are socialized into design patterns that have made them ineffective in civilian projects, ceteris paribus. ${ }^{13}$ Barriers to defense diversification have been linked to the segregation of military and civilian production. ${ }^{14}$ Such segregation helps explain the "great variety of dual-use" relationships. For example, at one point IBM kept "its Federal Systems Division at arm's length from its commercial business." In contrast, at Hughes "the same people make the same solar cells, batteries, attitude control

systems, structures, and RF payloads and assemble them in the same facilities into both military and commercial communication satellites." 15

Technology is not simply embedded in places; it is born of scientific and engineering personnel who can migrate across divisional barriers as part of matrix organizations or floating labor pools. While divisions may be separated for accounting or administrative reasons, key personnel can move from defense to civilian organizations and vice versa. ${ }^{16}$ The key question for diversification then becomes how such scientific and engineering staff is trained and managed, and what is the role played by organizational innovations. Some defense companies can learn how to handle differences between military and commercial applications, but even after doing so others can be constrained by managerial interference. ${ }^{17}$

These managerial constraints occur because competition over financial and human resources - key ingredients for developing any new product - is a central part of the innovation process. ${ }^{18}$ Higher-level, more powerful managers controlling such resources can limit access to them by weaker, lower-level managers. Some also argue that engineers' ability to innovate can be limited by manager's incompetence, interference, and sabotage.${ }^{19}$ Some dual-use proponents acknowledge that the national defense mission is fundamentally different from the goal of promoting economic competitiveness. The inability to harmonize these goals means that support for one must often be at the expense of the other. ${ }^{20}$

Nanoquest's resources: evolution and organization in the British Aerospace network

Nanoquest Defence Products Ltd. was formed in the United Kingdom in July 1990 , with the acquisition of Nanoquest Products Division of Bio-Rad Laboratories of the United States. ${ }^{21}$ The firm started off as a strictly military-oriented firm that produced tank and artillery sights, having a strong presence in the military land market. It grew by taking over technologies developed by other military operations in the British Aerospace Enterprises family of companies. Nanoquest assumed responsibility for Reflectone and BAe Simulation's Laser Dome projectors, a product used by the other firms in their Dome Simulators. ${ }^{22}$

In 1987, British Aerospace Enterprises acquired for $£ 17$ million a German-based 
firm of about 300 persons, called Steinheil Optronik GmbH. ${ }^{23}$ Even though that firm eventually closed down in mid-1994, Enterprises used Steinheil to establish Nanoquest as a Steinheil subsidiary. Steinheil supported Nanoquest with financial assistance and by providing production and marketing capacity. Nanoquest - at one point a group of thirty to forty employees - took over technology that had been developed by Steinheil. Steinheil had developed an expertise in infrared technology. One key product, a thermal imaging camera, was an ideal compliment to Nanoquest's existing portfolio. As a significant part of Nanoquest was based on Steinheil technology, it is important to understand why Steinheil transferred its technology to another firm and was eventually closed down. These reasons help partly explain how Nanoquest succeeded and gained managerial support from BAe. One Enterprise manager had wanted Nanoquest to be taken over by Steinheil, but various factors, elaborated below, prevented this from happening.

First, the company faced dramatic cutbacks from the German Ministry of Defense (MoD) and ran out of cash before it could diversify. The cash shortage was not only based on post-Cold war cuts. In addition, Steinheil was late in developing military technologies already taken up by competitors. It had developed night sights to complement its day sights, but by the time they had put a product on the market other German firms had already developed night vision technologies. The cash shortage put a dent in Steinheil's diversification efforts.

Second, Nanoquest's managing director, Paul Johnson, was highly entrepreneurial. He had experience in civilian markets, having worked on commercial optical systems for Xerox copying machines, engraving machines, LCD and fibre optics, including a brand-new product for motorway signing. He worked with sales teams to provide technical support and also had engineering experience and training. Johnson also worked as a manger for military firms, allowing him to understand the requirements of both defense and civilian markets.

Third, Steinheil was even more military-oriented than Nanoquest. They were accustomed to getting orders from the German MoD and had difficulties in diversifying. Steinheil had used Nanoquest as a selling arm for their products, so Nanoquest was encouraged to cultivate marketing skills. Nanoquest originally sold to original equipment manufacturers, not defense ministries, creating a commercial know-how even in their original military market. Nanoquest was established as a small firm with a more commercially-oriented environment. This became important because the military market for Steinheil products was rather competitive. ${ }^{24}$

Nanoquest was able to capitalize on Steinheil technologies using different strategies. The process of technology transfer and innovation was facilitated and sped up as each firm shared the same computer-aided design system and used the same set of suppliers. Sharing suppliers made component testing easier and reduced risk. Nanoquest manufactured its night vision commercial camera to military specifications and became successful by taking Steinheil's technology and placing it in a new, smallfirm environment. In January 1998, BAe established an incubator and marketing- support organization called British Aerospace Enterprises. This network linked the first-tier, core prime-contractor of BAe to small and medium-sized defense firms it owned. Nanoquest was typical of many diversification projects that start with a limited number of innovators and support staff, but gradually increase in size if market penetration is successful.

British Aerospace Enterprises represented the creation of an internal corporate network open to the promotion of dual-use products or technologies, such as supply trucks that can be used in commerce and in war. The initiative never had any important relationship to external trade union initiatives to promote conversion. Enterprises' diversification strategy was not without flaws but did represent an advance over simplistic strategies that co-located civilian and military production in high-cost and high-overhead production platforms. (Later on, the article discusses the relevance of Nanoquest to debates about the civilian promise of defense conversion and diversification.)

Nanoquest substantially reduced its military dependency over an eight year period. Nonetheless, the company eventually was folded into BAe and its independent identity disappeared. The company is representative of many diversification projects which often begin as smaller firms with a limited group of innovators and face political barriers in gaining diversification resources or development free from managerial interference. ${ }^{25}$

\section{Relatedness}

\section{The evolution of relatedness in Nanoquest's diversification}

After primarily being dedicated to military markets, Nanoquest decided that they could not compete there. In military markets, their competitors included larger companies and more established suppliers like GEC Marconi and Pilkington Optronics. Nanoquest learned from Steinheil that competition from such companies helped drive prices down in military markets. This encouraged Nanoquest to pursue newer, less established commercial markets in continental Europe.

Nanoquest pursued one key commercial market: night vision surveillance equipment mounted on Volkswagen vans. A new market for this equipment emerged with the signing of the Schengen agreement that created open borders within Europe. This led governments to increase border patrols to control drug imports and illegal immigration. This market for paramilitary sales resembled a traditional military one in that both involved security needs and government purchasers. Nanoquest's customers included border police and the national governments of Germany, Hungary, and Austria. Despite such similarities, there were important differences between Nanoquest's commercial market and that found in traditional BAe defense sales (see Table 1).

Nanoquest's skills were selling, designing, assembling, and delivering products 
and services. Subcontractors made parts for components like cameras. Thus, the fungibility or transferability of design skills, linked to various organizational innovations, provided a foundation for developing new technologies and customers. Yet, the ability to use common resources in military and civilian markets proved to be insufficient for long-term success.

\section{Synergies and relations with $B A e$}

BAe's army weapons division might have been able to support Steinheil Optronik's optics and electronics capability but refused to cooperate with them. ${ }^{26}$ Nanoquest's ability to enter certain markets was initially delayed, if not prevented, when it was of key strategic importance to the mother firm, BAe. British Aerospace managers would attend any Nanoquest meetings with customers in the Middle East because BAe was very reliant on customers there, such as those in Saudi Arabia, which had helped BAe in the past: "they didn't want a smaller company to screw it all up." For this reason, BAe wanted to know exactly what its smaller parts were doing and where they were going. Their interest was in selling big airplanes, not a smaller item, in this case a vehicle with a camera on it. ${ }^{27}$ Fears of conflicting with customers created a problem in forging synergies with the smaller firm, a problem independent of so-called transaction cost considerations.

In other areas, there were positive synergies between Nanoquest and BAe. Nanoquest had access to the BAe International Sales Organisation and their intelligence. The BAe name helped open doors and provided access to potential new customers. It helped in securing sales for customers to know that, although they were dealing with a small firm, BAe as a larger firm could back them up and support them. Unlike BAe, however, as a small company Nanoquest had a low-cost base with competitive prices. Nanoquest was also able to exploit British Aerospace's purchasing power via its central purchasing organization. The organization negotiated discounts for materials and supplies from a long list of companies, e.g., renting cars and health care plans.

A major problem was that divisions that did not do what company leaders wanted, were not given funding, or would have to go to extreme lengths to get funding. The top military-oriented managers based at the firm's headquarters controlled most of the firm's resources, so any other division "was a poor relation to them." Richard Evans, former British Aerospace chairman, confirmed a part of this assessment. In his book, he quotes Richard Lapthorne, former Director of Finance, as saying, "we had baronies all over the place." These power wielders influenced technology transfer and intra-firm relations: "the lacuna at the heart of BAe [was] the lack of personal ties, mutual support, shared knowledge." Even though business units were aware of one another, trading business and services, "antagonism and rivalry invariably marred these relationships." Another top manager quoted in the book says, "five years ago all you'd have had were two bits of BAe completely at war with each other." 28
Table 1: How Nanoquest grew and diversified: the limits of relatedness

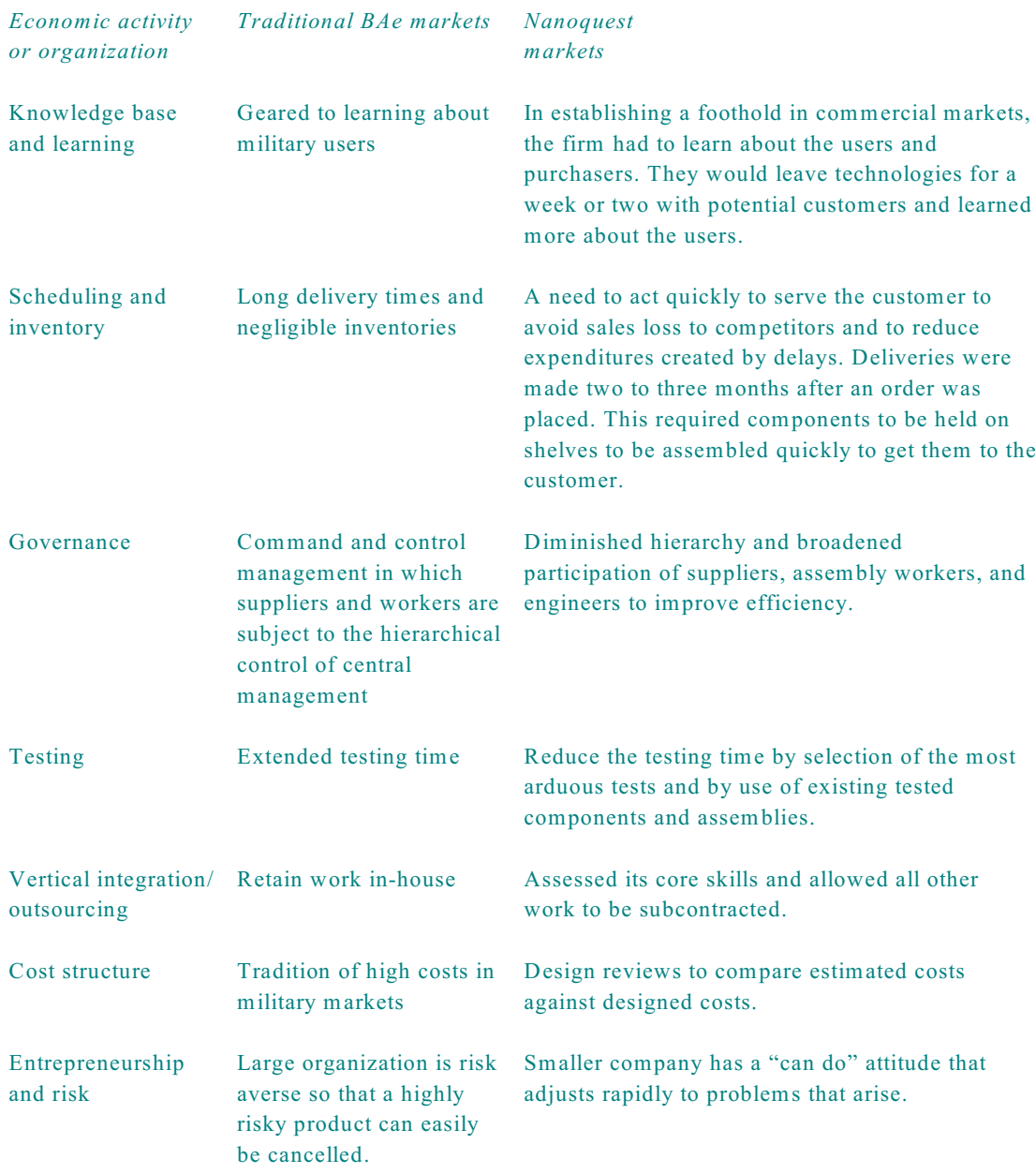

Scheduling and

inventory

Long delivery times and negligible inventories

Governance

Command and control management in which suppliers and workers are subject to the hierarchical control of central management

A need to act quickly to serve the customer to avoid sales loss to competitors and to reduce expenditures created by delays. Deliveries were made two to three months after an order was placed. This required components to be held on shelves to be assembled quickly to get them to the customer.

Diminished hierarchy and broadened participation of suppliers, assembly workers, and engineers to improve efficiency. Extended testing time

Reduce the testing time by selection of the most arduous tests and by use of existing tested components and assemblies.

Vertical integration/ Retain work in-house outsourcing Assessed its core skills and allowed all othe work to be subcontracted.

Cost structure Tradition of high costs in military markets

作 against designed costs.

Entrepreneurship and risk

Large organization is risk averse so that a highly risky product can easily be cancelled.

Smaller company has a "can do" attitude that adjusts rapidly to problems that arise.

Source: Author, based on Johnson (2000).

The power behind learning and diversifying: managerial politics of British Aerospace Enterprises

The Nanoquest case sheds light on the utility of British Aerospace Enterprises as a support organization for diversification. Paul Johnson, Nanoquest's manager, found 
that British Aerospace Enterprises "didn't seem well respected" by the other major divisions. This led him during his first two or more years as managing director to market his firm's capacities directly to each of the BAe divisions. Despite this, Enterprises became a gateway for gaining information about technology and markets within British Aerospace. For example, the network opened doors for Nanoquest by putting them in touch with contacts in the Far East and Middle East. Enterprises gave its smaller firms clout for accessing resources in the larger firm British Aerospace.

Ian Irving, a key Enterprise manager, helped Nanoquest in marketing and business development. He sat on the Nanoquest board and was readily accessible in providing good, practical business advice. His huge network of contacts with commercial businesses was helpful. If Mr. Johnson had a problem, needed access to someone in British Aerospace, or market help, he could readily get this from Mr. Irving and Enterprises. Enterprises also provided help with publicity and exhibitions.

In 1994 B Ae decided to sell Steinheil but retained Nanoquest. Nanoquest was then charged to fund product development based on its own profits. This limited growth, but Johnson compensated for the problem by sharing (when possible) the cost of development with partners like Vickers (in the case of sighting equipment for the Challenger 2 program) and Royal Ordnance (in the case of artillery sighting systems) This approach proved to be very successful and allowed new products to be developed and enhanced existing products.

Johnson observes that "when you're a small company and transfer to a big company it doesn't always work ... Enterprises was trying to solve the problem" of linking a small company to a large one and helped mesh the different corporate cultures. Enterprises had several advantages as an immediate parent to Nanoquest. Unlike BAe, they recognized the need for flexibility, good service, and rapid responses required in the marketplace. Enterprises allowed Nanoquest to operate freely as long as the company remained profitable and the business grew.

In contrast to Enterprises, the central headquarters of British Aerospace played a more interfering role. After the company's first week, every week headquarters wanted a report on sales, cash flow, profit, and cash in bank to the nearest million. Nanoquest only generated thousands of pounds at that point, leading them to fill in reports with a series of zeros. Enterprises was useful, Johnson explains, "because they protected me from the Big Brother ... They went in front of Big Brother and pointed out to them, 'this isn't helping to run the business at all'." Such reporting would take on the order of half a day a week for Nanoquest's financing director. The reporting activity was not proactive, failing to lead to suggestions about new directions, but was more "disciplinary" in function, representing a form of internal regulation without feedback. Enterprises also protected Nanoquest "because anything that came from head office had to come through Enterprises." The parent firm also wanted detailed information about the countries and customers of Nanoquest but here again Enterprises interceded and prevented interference. ${ }^{29}$

After Enterprises was dismantled, Nanoquest became part of the large-firm culture. Mr. Johnson eventually took early retirement, because of demands placed on him by the new big-firm management. His new managing director wanted to create reorganization plans that did not make sense for a firm that had already changed its culture. Johnson then had to protect his firm from the bigger BAe through endless meetings and reports. During the post-Enterprises period, Johnson had to report to the Treasury Department in the British Aerospace head office. He reported to three separate persons there over a nine-month period. This group collected information but provided no guidance or support. No one commented on or provided approval for his long-term plans for the firm, needed to set company strategy. Managers at Enterprises, in contrast, were familiar enough with the business to provide approval. The Treasury Department was more interested in financial figures, not engineering and development issues. The Treasury Department was myopically focused on getting the finances "to look right."

Did diversification barriers or intra-firm politics thwart success?

Enterprises manager Ian Irving says that Nanoquest was among the two most successful of the diversification network's member firms. ${ }^{30}$ In 1995, Nanoquest Defence Products Limited became part of British Aerospace Systems and Equipment Limited..$^{31}$ In 1996, the company reached its high point in sales because it was involved in contracts that applied sighting equipment for the new British Challenger 2 tank. ${ }^{32}$ In 1998, the company experienced a major loss because the parent British Aerospace prevented Nanoquest from negotiating better conditions on an order in the highly competitive Austrian market. Manager Johnson explains: "We were due to

Table 2: Nanoquest's performance, 1991-1998 Sales in £s Employees Operating Product Defense development dependency budget in $£$ s (in \%)

$\begin{array}{rrrrrr}1991 & 2,167,000 & 29 & 230,000 & 65,000 & 100 \\ 1992 & 2,367,000 & 30 & 403,000 & 88,000 & 100 \\ 1993 & 3,170,000 & 30 & 490,000 & 78,000 & 100 \\ 1994 & 3,050,000 & 34 & 580,000 & 194,000 & 100 \\ 1995 & 4,025,000 & 35 & 662,000 & 185,000 & 100 \\ 1996 & 7,030,000 & 50 & 1,168,000 & 376,000 & 95 \\ 1997 & 4,670,000 & 53 & 817,000 & 521,000 & 85 \\ 1998 & 3,968,000 & 52 & (150,000) & 360,000 & 60\end{array}$

Note: All figures are in nominal terms, not inflation adjusted. Source: Johnson (2000) 
The Nanoquest case reveals that internal politics and power structures can block success. They define barriers to diversification even when military and civilian technologies are related.

nevertheless established a record of steady revenue growth and profit under Johnson's tenure (see Table 2 on p. 60).

\section{Conclusion}

This case study contributes to an understanding of the dynamics of conversion and diversification processes in defense firms. While not a case of conversion associated with demilitarization, it does show that technical barriers do not necessarily prevent successful development of civilian markets. ${ }^{33}$ It reveals that internal politics and power structures can block success. These define barriers to diversification even when military and civilian technologies are related.

The role played by different technological actors, managerial groups, and individuals who shape diversification or technology transfer outcomes was highlighted. Through the bridging activities of top-manager Johnson, Nanoquest was able to overcome some of the learning, marketing, and managerial challenges associated with defense specialization. His experience in both military and civilian firms helped Nanoquest overcome specialization, as did his ability to make distinction between military and civilian corporate requirements. Nanoquest was able to combine profitability and diversification into nonmilitary markets during the late 1990 s, although interference by higher-level managers later made it difficult to link (in an accounting sense) firm performance to actual innovative activities.

The Nanoquest case shows that even when a defense firm diversifies using a base of markets and products similar to those in military markets, it can still face internal political barriers. The ability to diversify even in areas that built upon militarytechnological relatedness was constrained by wider considerations of politics and markets. At the same time, organizational innovations and firm structures promoted innovation and diversification. Nanoquest as a smaller firm gained a certain degree of flexibility. British Aerospace Enterprises bridged the divide between small and large firm and even between the core firm and the more downstream operations of Nanoquest as a supplier of key components. Thus, the network form of Enterprises and its support role challenges characterizations of defense barriers that are based on a simple static picture of the defense firm and divorced from its larger (supporting) environment. BAe sometimes provided synergies and the Enterprises network offered valuable contacts, or social capital, but such network ties were ultimately insufficient in the face of weak political capital vis-à-vis top BAe managers. ${ }^{34}$

\section{Notes}

Jonathan Michael Feldman is a lecturer in the Department of Economic History at Stockholm University in Stockholm, Sweden. He thanks Jordi Molas-Gallart for his detailed observations and the editorial reviewers for helpful comments.

1. This case study is based on interviews with key managers, who are identified later on, at BAe and Nanoquest. It focuses on the why and how questions related to organizational change. My final draft and interview notes were reviewed by these managers during the course of my research.

2. Of course not all dual-use scholars make the same claims. This article is directed against the arguments that: (a) defense firms' shift into civilian markets is relatively easy; (b) take an ahistorical view of how firms' capacities develop; or (c) ignore the history behind how military and civilian capacities become more related.

3. These include management theorists like Burns and Stalker (1994).

4. Economic conversion (in the U.K. also known as defense or arms conversion) refers to the political, economic, and technical process of shifting to civilian products and markets. Such conversion can take place in industrial enterprises, laboratories, university research departments, and military bases. Whereas diversification promotes the entry into new markets (military or civilian) by acquisition or internal product development, conversion emphasizes civilian markets and has been less associated with acquisition strategies or strategies that do not promote the retraining and reuse of existing workers. Nevertheless, often conversion depends on diversification or the acquisition of resources external to the firm because specialized defense firms lack knowledge or access to relevant expertise, specialized skills, distribution channels, or other key capacities. Some proponents of diversification do not care if military workers are retrained for new jobs within the company when defense firms enter new markets. Others are indifferent if the defense firm diversification supports a new generation of military (as opposed to civilian) technology. Conversion, in contrast, is linked to the ideas of disarmament and trade union protection of employment possibilities. For more discussion of conversion, see Feldman (2006), Melman (2001), and Schofield (2007).

5. Labour Party (1995), as cited in Spinardi (2000, p. 129).

6. Feldman (1998; 2006). 
7. Te Kulve and Smit (2003).

8. Kelley and Watkins (1995).

9. Molas-Gallart (2006, p. 170).

10. Carter (1988, p. 8).

11. Feldman $(1998 ; 2006)$. At certain times, civilian diversification goals gain in importance, particularly during military budget downturns. The failure of diversification efforts, mergers among defense companies, and divestitures of civilian divisions each help strengthen the hands of military-oriented top managers.

12. Dumas (1986); Melman (1983).

13. Melman (1983).

14. Markusen (1991).

15. All quotes from Carter (1988, pp. 4-5).

16. Alic, et al. (1992); Feldman (1998; 1999a; 1999b; 2006).

17. Feldman (1999a; 1999b; 2006).

18. Burns and Stalker (1994).

19. Veblen (1965); Melman (1983).

20. Alic, et al. (1992).

21. BAE Systems (2007a; 2007b).

22. Unless otherwise indicated, this account is based on interviews with Hooke, Irving, and Johnson (all 2000). My findings reflect patterns and causal relationships I have identified in other cases in American and Swedish defense firms.

\section{BAE Systems (2007b).}

24. Some argue that the other side of Enterprises' success with Nanoquest was B Ae's failure with Steinheil. BAe acquired the firm because they thought they could help it find new markets and diversify. It was placed first in BAe's Dynamics group, but was resented there because Dynamics had not made the acquisition. Eventually, Steinheil was inherited by Enterprises. An original plan that would have had Steinheil using Nanoquest as a basis for diversification was abandoned.

25. Feldman (1999a; 1999b; 2006).

26. Fraser (2000).

27. Johnson (2000).

28. Evans and Price (1999, pp. 11, 25, 125).

29. Johnson (2000).

30. Irving (2000).

31. BAE Systems (2007a).

32. It is useful to note that military-linked budgets, R\&D, financing, and capital are often used by successful defense diversification projects as a kind of banking system. In the absence of a supporting civilian industrial policy, access to military contracts and profits is often critical. This fact does not mitigate the diversionary aspects of military spending (see Dumas, 1986; Melman, 1983).

33. This case highlights how defense engineering staff can be retained in new markets, although some flexibility was gained through subcontracts. It shows the incentives for diversification despite potential barriers rooted in global markets. In a period of restructuring, smaller defense firms can just as easily face global competition from larger military firms. Thus, sticking to military markets to sidestep global competition in civilian markets is not always an option.

34. See also the discussion in Webb (1998).

\section{References}

Alic, John A., Lewis M. Branscomb, Harvey Brooks, Ashton B. Carter, and Gerald L. Epstein. 1992. Beyond Spinoff: Military and Commercial Technologies in a Changing World. Boston: Harvard Business School Press.

BAE Systems. 2007 a. "Evolution of the Company." http://www.bae-systems.com/facts/awards/evolution.htm and http://www.bae-systems.com/facts/awards/evolution3.htm [accessed 29 May 2007]. 


\section{B A E Systems. 2007b. "About Us: Our Evolution."} http://www.bae-systems.com/aboutus/evolution.htm [accessed 2 September 2007].

Burns, Tom and G. M. Stalker. 1994. The Management of Innovation. Oxford: Oxford University Press.

Carter, Ashton. 1988. "Introductory Remarks at the Workshop on Dual-Use Technologies: International Perspectives." Sponsored by the Dual-Use Technologies Project, Science, Technology and Public Policy Program, John F. Kennedy School of Government, Harvard University, Cambridge, MA, October 21-22. Reprinted as Science, Techology and Public Policy Program Discussion Paper 89-05.

Dumas, Lloyd J. 1986. The Overburdened Economy: Uncovering the Causes of Chronic Unemployment, Inflation, and National Decline. Berkeley, CA: The University of California Press.

Evans, Sir Richard and Colin Price. 1999. Vertical Take-Off: The Inside Story of British Aerospace's Comeback from Crisis to World Class. London: Nicholas Brealey Publishing.

Feldman, Jonathan Michael. 1998. "The Conversion of Defence Engineers' Skills: Explaining Success and Failure Through Customer-Based Learning, Teaming and Managerial Integration," pp. 281-318 in Gerald I. Susman and Sean O'Keefe, eds. The Defense Industry in the Post-Cold War Era: Corporate Strategy and Public Policy Perspectives. Oxford: Elsevier Science.

Feldman, Jonathan Michael. 1999a. "Can Saab Diversify? Lessons from Civilian Spinoffs in the 1970s and 1989s." Working Paper, Department of Technology and Social Change, Linköping University, Linköping, Sweden, March.

Feldman, Jonathan Michael. 1999b. "Civilian Diversification, Learning and Institutional Change: Growth Through Knowledge and Power." Environment and Planning A, Vol. 31, No. 10, pp. 1805-1824.

Feldman, Jonathan Michael. 2006. "Industrial Conversion: A Linchpin for Disarmament and Development," pp. 193-217 in Gustaaf Geeraerts, Natalie Pauwels, and Éric Remacle, eds. Dimensions of Peace and Security: A Reader. Brussels: Peter Lang.

Fraser, Ian. 2000. Former Director, British Aerospace Enterprises. Interview with author, 25 February; communication with author, 4 April and 9 June.

Hooke, Richard. 2000. Former New Ventures Director, British Aerospace Enterprises. Phone interview with author, Surbiton, England, 7 April, and London, England, 18 April and 2 May.

Irving, Ian. 2000. Former Business Development Director, British Aerospace Enterprises. Interview with author, Stevenage, England, 6 March; email communications to author, 30 March and 19 April; phone interview with author, 17 April.

Johnson, Paul. 2000. Former Managing Director, Nanoquest. Interview with author Leeds, England, 2 March; communication with author 2 March, 30 March, and 26
April.

Kelley, Maryellen R. and Todd A. Watkins. 1995. "The Myth of the Specialized Military Contractor." Technology Review, Vol. 98, No. 3, pp. 52-58.

Labour Party. 1995. "Strategy for a Secure Future.” London: Labour Party.

Markusen, Ann. 1991. "The Military-Industrial Divide." Environment and Planning D: Society and Space, Vol. 9, No. 4, pp. 391-416.

Melman, Seymour. 1983. Profits without Production. New York: Alfred A. Knopf. Melman, Seymour. 2001. After Capitalism: From Managerialism to Workplace Democracy. New York: Alfred A. Knopf.

Molas-Gallart, Jordi. 2006. "Military Technology and Dual-use," pp. 165-176 in Gustaaf Geeraerts, Natalie Pauwels and Éric Remacle, eds. Dimensions of Peace and Security: A Reader. Brussels: Peter Lang.

Schofield, Steven. 2007. "Oceans of W ork: Arms Conversion Revisited." London and Washington, DC: British American Security Information Council.

Spinardi, Graham. 2000. "Prospects for the Defence Diversification Agency: Technology Transfer and the U.K. Defence Research Establishments." Science and Public Policy, Vol. 27, No. 2, pp. 123-135.

Te Kulve, Haico and Wim A. Smit. 2003. "Civilian-Military Co-operation Strategies in Developing New Technologies." Research Policy, Vol. 32, No. 6, pp. 955-970.

Veblen, Thorstein. 1965. The Engineers and the Price System. New York: A. M. Kelly.

Webb, Tim. 1998. The Armour-Plated Ostrich: The Hidden Costs of Britain's Addiction to the Arms Business. West Wickham, Kent: Comerford \& Miller. 